\title{
“A Raft in the Stormy Sea”: New Roles, New “Dresses” Operating in \& for Business Networks
}

\author{
Patrizia Riva \\ University of Eastern Piedmont, Novara, Italy \\ Roberta Provasi \\ University of Milan-Bicocca, Milan, Italy
}

\begin{abstract}
This paper aims to discuss the development and functioning conditions of business networks. After recalling the main characteristics of post-fordistic environment and comparing it to a "stormy sea" (section one) of the paper focuses on the idea of networks described as "rafts" useful to firms to build their own competitive advantages. In fact, while theoretical knowledge is not so valuable because everybody can have it, practical and contextual knowledge is specific and therefore it can be defended. The development of a contextual knowledge is feasible if the firm chooses among all the possible alternatives. Subsequently in section two, it shows how fordistic principles eliminate space, reduce time, and increase the speed of communication among individuals and as entering a network has become a necessity as it allows a firm to obtain competitive advantages. The greatest benefit is the chance to share the task of creating new knowledge among different members. In section three it is discussed if navigation in the post-fordistic stormy sea could take advantage from the existence of a more certain regulation. It is necessary to underline that positive law is not a post-fordistic tool. There is no satisfactory detailed law regarding ideas, knowledge, and know-how, by now. Therefore, it is not possible to rely on a specific regulation framework to protect knowledge found on the network. In conclusion in section four, the work discusses how single organizations need to reach the "raft" — which is the network—-through the idea of sharing learning and distinguishing elements necessary to survive in the stormy sea post-Fordism environment. Lastly, section five would be analyzed a public institution-Milan Chamber of Commerce—which has "changed its dress" to more effectively perform its support role to firms.
\end{abstract}

Keywords: post-Fordism period, pre-Fordism period, business networks, shared knowledge, competitive advantage, stormy sea, raft, Chamber of Commerce

\section{Scientific Progress and “ Weather Changes”}

The growing diffusion of information technology, personal computers, telematics and automatic machines constitutes a technological progress, opening a transition period from Fordism to post-Fordism. While new technologies dramatically reduce the information cost per unit, instantaneous transfers of a large amount of complex information become possible from a place to another, even in case of relevant distances. This

Patrizia Riva, Ph.D., Aggregate Professor, Economics and Business Studies, University of Eastern Piedmont.

Roberta Provasi, Ph.D., Aggregate Professor, Economics Science and Law, University of Milan-Bicocca.

Correspondence concerning this article should be addressed to Patrizia Riva, University of Eastern Piedmont, Via Perrone, 18, 28100, Novara, Italy. E-mail: patrizia.riva@eco.unipmn.it. 
phenomenon generates important consequences for organizations, because it changes the foundation of Fordistic institutions: It can be compared only to the discovery of electrical power.

\section{From the "Still Calm" of Fordism}

The pre-fordistic manufacturing system was based on the presence of a steam power machine, hampering and expensive, to which every other machine of the plant was linked. Therefore, each plant was conceived as a unique large machine, formed by the power plant and a limited number of machines working synchronously. Its functioning was based on theoretical principles, more or less directly derived from chance and technologic; it was not easy to adapt it to different and changing resources and customer expectations. The basic knowledge had a theoretical nature. On the contrary, everyday practice was not relevant, because machines were not able to considerate it. Therefore, workers were completely alienated: Their personality was completely subjugated by manufacturing machines and labor was merely considered as "manpower time", a standardized factor measurable in man-hours, independent from individual skills. The discovery of electrical power allows the separation of single machines: The turbine motions are not directly transmitted to the machines, but it is converted into electrical power that can immediately circulate through a wide network, at low costs. This means that it is possible to operate an industrial plan virtually everywhere and not only in a specific place. The layout of the single plant can be modified, too: Machines need not be all linked to a central power source. They operate in a more autonomous way and once merely mechanical schemes can be adapted to specific contexts. Technological progress thus allows adaptation to practical and specific needs: The ability in combining different machines in new and original ways now becomes critical. Thus, the fordistic firm can partially recover the practical knowledge and characterizing the old handicraft laboratory.

On the one hand, it standardizes micro operations (it splits basic operations), but on the other hand: it designs macro processes by considering individual skills. Practical knowledge allows differentiation: The firm can build its own competitive advantage. In fact, while theoretical knowledge is not so valuable because everybody can have it, practical and contextual knowledge is specific, cannot be copied in a short time and in a cheap way, and therefore it can be defended . The development of a contextual knowledge is feasible if the firm chooses among all the possible alternatives: It must decompose complexity by selecting specific opportunities and not other once. Choices are irreversible because so are investments made and product characteristics. The selected course of action must be strictly followed according to the decision taken. This is particularly true also because the existence of a specific know-how produces real benefits for the firm only if completely utilized. Therefore there is an incentive to exploit relevant investments made, in other ways not recoverable, by pursuing economies of scale and integration. A strong tendency to dimensional growth is evident at this stage. This is possible by utilizing a hierarchical organizational structure based on centralization and coordination of the single parts of the firm through planning. Planning and control systems ensure efficiency to the firm, so that it moves towards the expected direction, but at the same time the firm cannot change its way according to new circumstances.

Fordism means confidence and certainty. Metaphorically speaking, it can be considered as a period in which large ships with no radar-big multidivisional companies_navigate along planned routes, on a calm sea and in favorable weather conditions. An environmental change is simply not conceived and it can hardly be effectively faced: navigation therefore means great and unavoidable risks.

\section{To the "Stormy Sea" of Post-Fordism}

The creation of art electronic power network allows to split physical operations, because the single spots 
where electricity is utilized become independent from each other. However, it is still not possible to share the information needed to compose single operations as a system, through a network. For this reason, information is managed in a centralized way. The transition towards a post-fordistic system starts when technology advances allow the development of an information to split information, too. Information technology tools, such as personal computers and Internet and Intranet communication systems, when utilized on a broad scale, allow the codification of knowledge developed in a certain place and its use by many people located in different sites. There are many implications of this phenomenon, because it allows to go beyond the fordistic model. New information technology allows: (1) a virtual decomposition of complexity (of products, manufacturing processes, working stages, and job tasks), obtained through the use of modular virtual objects representing single components of a product/process; and (2) a new composition of single parts through virtual components, in order to build tailored solutions using the same samples of virtual objects. Information, like electrical power should circulate within the system: As the latter allows the creation of separate manufacturing centers, the former today allows the creation of independent knowledge creation centers. Complexity is not a problem anymore the firm is not obliged to choose one opportunity once and forever, asking the risk to make hardly recoverable investments, aimed at following binding decisions with uncertain results. Frustration, derived from the need for planning and control and from the observation that complexity cannot be reduced only to controllable dimensions, decreases instead, the firm is pushed towards the continuous generation of new complexity by creating very different new alternatives. This is possible because manufacturing is not the focus of the entire process of creation any more, but it is only the final stage. On the contrary, the most important stage is represented by the use of "pieces of information" circulating through the network, in order to try new possible solutions. As nothing "physical" is really created and "pieces of knowledge" are available within the network, investment in new tests is very cheap, virtually equal to zero, and it is possible to simulate different solutions to meet the expectations of different stakeholders, of clients in particular. Firms must create value for clients, by designing more and more tailored solutions, based on the analysis of their expectation.

Firms nowadays pursue economies of differentiation. They originate from the fact that tailored products generate a larger amount of value to the user. What makes the new modus operandi possible and revolutionary is the reversibility of products. Everything is possible until it remains in the "world of ideas" and is not completely implemented. Therefore, the opportunity to generate new ideas and to create "new things" is systematically pursued: It is not a threat anymore and it becomes a new life and new aim for the modern firm. We can state that post-Fordism means uncertainty and pursue of the new, of the never tried, and of continuous changes.

Metaphorically speaking, it can be viewed as a period of violent storms, in which fordistic favorable weather conditions and still calm have disappeared. Large ships, still following pre-determined routes, have already sunk or are facing enormous difficulties. In this context, survivors can continue their navigation only by creating new and quicker ships.

\section{Business Networks: “A Raft in the Stormy Sea”}

The post-fordistic model dramatically chances fordistic principles: It eliminates space, reduces time, and increases the speed of communication among individuals. The network is a virtual space where interaction takes place and new knowledge is created. It is composed by a certain number of subjects, by reciprocal relationships and by shared information. Its existence is not based on physical because it uses virtual 
communication and links subject physically very far from each other. A subject belongs to the network if it is able to generate specific meanings, together with other members, and share with them the same language. The boundaries of the network can be set in a more or less flexible way. When specific criteria to enter the network are set, the network is "closed".

Within this organizational model, job tasks are shared out according to knowledge criteria, and not according to material ones. Each network junction specialized in a particular task spreads its specific knowledge within the network, so that other members can use it. The information/communication potential of the whole network continuously increases ${ }^{1}$.

Entering a network has become a necessity, because each firm cannot autonomously generate enough information to ensure its survival in a continuously changing and very competitive environment, such as the post-fordistic one. However, it is important to underline that, while entering a network allows a firm to obtain competitive advantages, by exploiting "knowledge reserves" generated by other subject, this is enough for survival. No certainties in post-Fordism: Everything is changing, the network included.

Metaphorically speaking, in post-fordistic stormy sea, navigation is possible only by a thin raft. Its survival among the waves is more probable than the one of ships. Riding waves on it is easier than simply swim in solitude among them.

\section{You Need Wood to Build Your Raft}

The length of the transition period between Fordism and post-Fordism depended on the speed of diffusion of the telematic networks. Standing apart means to be condemned "to swim in solitude among the waves", increasing the level of risk. It seems much better to build some kind of boat-rafts—even if not so safe, because they are less risky than just swimming. This becomes possible as:

- "Wood" that is the information telematic network dimensions increases;

- The potential users know that "wood" is needed to "build rafts": The culture of telematic communication and networks widely spread. Benefits of network way to operate have been clearly shown.

\section{If You Wish Your Raft to Float}

The greatest benefit that derives from the opportunity to build a network is the chance to share the task of creating new knowledge among different members. It has also been underlined that in post-Fordism, subjects are obliged, in order to survive, to enter the network, and to rely on others because they realize that nobody, standing alone, owns enough skills to control complexity. The need to enter a network not automatically ensures that it will correctly work as a system. Paradoxically what seems to be a strength of new technologies, that is the possibility to reach many different subjects, could become a weakness. As already underlined, the task of creating knowledge can be effectively shared if a new knowledge, developed in a particular part of the network, is made available to the others, so that whoever needs it can find it in that specific net junction. From a practical point of view, there are several obstacles to this diffusion. The diffusion can take place if:

(1) The system ensures participants the recognition of the value of knowledge brought in the network.

As a shared knowledge has no economic value, bringing new knowledge in the network means no recover of the investments made for it. It is then necessary that the network system becomes able to recognize the real economic value of created and shared knowledge. At this point, typical aims of the enterprise contrast with the network logic: Firms specifically want to increase profits, differently from scientific laboratories. A firm needs

\footnotetext{
${ }^{1}$ This statement is widely discussed in this paper, particularly in section five.
} 
to sell its knowledge and convert it into profits. It has a need to implement an appropriation of knowledge and of its related, a need that does not exist in such an evident way in the scientific world. There is a specific contradiction in the industrial economy: Facing the convenience to share information as a productive strength, there is the convenience to limit this sharing, in order to use it exclusively. To go beyond this conflict the strength of transferable knowledge should permeate the network, generating a far profit for its author (Rullani \& Di Bernardo, 1990).

(2) It is possible to trust on a minimum quality level of knowledge brought in the network and of the modus operandi globally considered by network members.

The reliability of the counterparts is absolutely necessary to ensure a correct functioning of a network. Admission of subjects not able to ensure qualitative standards comparable to other members' causes a loss of effectiveness and competitiveness of the network and all its components. Somebody says that these goals can only be reached through a new transformation of a network into a hierarchy. The only way, according to these authors is "to establish rules, enforce and support them through the menace of a compulsion" (Coleman, 1998). This does not seem to be a necessary conclusion. There are other solutions, of different nature. However in order to accept the existence and to understand them, you need to abandon the fordistic way of thinking and to rely on new post-fordistic concepts. This is what we intend to do in the next part of our essay.

\section{You Need Cooperation, but You Do not Have Time to Build Trustworth Relationship}

Post-Fordism produces energy, creates opportunities never conceived before, but at the same time generates a terrible anguish. While the risk of having invested in just one option is eliminated, other issues arise. Firms must be able to continuously to create new ideas, because this is the only element differentiating them from competitors. In this creative process, firms are not and must not be self-sustaining, because they do not possess the potentially useful knowledge. Therefore, to achieve their objectives, firms must rely on others. The dependence is risky: They are obligate to search in the network for skills necessary for their survival, as they are not internally available. A selection of a certain number of partners, with which to establish on-going long-period relationships, can be a way of reducing risk, as in a Japanese network model. In this particular situation, subjects taking part in the network constitute a community sharing a set of ethical principles, to ensure a regular and fair behavior. Japanese networks become a new way of creating "a social capital", that is the ability of people to work together for common goals, to associate, to share rules and values, and to subordinate individual interests to group interests. It is formed by a not too large number of partners, which share an environment, because they usually operate in very well-defined geographical areas.

In the post-fordistic era, firms do not benefit from this way of acting. Instead of improving the situation, they will find themselves caged in "old fordistic schemes": In exchange for the illusion of a stronger steadiness, they will renounce to freedom, accepting the authority of others. A network based on this kind of informal organization, which makes the firm feel that its loyalty belongs to a protecting work group, is very similar to the one formed by large ships we talked about. Probably, for this group, navigation in the stormy sea, described in the third model, will be very difficult. Within a post-fordistic network, based on the use of telematics, it is not possible to develop long-term relationships among partners, unlike in Japanese networks, and therefore it is not possible to create a trusty relationship either. What induces a firm to interact with another one is a recognition of the intrinsic value of its knowledge and of its ability to create a new one. The aim of interaction is in fact to search for knowledge to combine, to obtain a more satisfactory product design and, then, a better 
implementation. Time is extremely important. As specific abilities can be found on the network, they are available to a large number of subjects. Therefore, probably more than one subject operating on the edge of new knowledge is likely to achieve similar and comparable results. Thus, it is not wise to wait for an old partner to develop new technologies, new shapes, and new ideas. If there are not, they must be searched for somewhere else. The opportunity to rely on the telematic network and then to contact many potential counterparts located somewhere else, makes it possible that somebody else, somewhere else, has developed specific knowledge in that particular field. Not to take advantage of it would be completely irrational, because it would mean to renounce to its own competitive advantage and therefore to renounce to survive "in the post-fordistic stormy sea”.

It is interesting to underline that firms interact within the network, but that virtually they stand alone they decide the knowledge to use, both when they design their products, and when they decide which knowledge to use, both when they design their products and when they introduce them on the market. Therefore, in post-Fordism every firm faces a very strong competitive pressure. The ability to generate complexity and to find innovative solutions is the only effective defense weapon. In other words, it is possible to state that the firm can only rely on the belief that other partners find it "interesting" and "able" and think that it is worthy interacting with it. A decrease in the level of attention implies the exclusion from the game and the potential failure. If on the one hand it is reasonable to abandon the subject we interacted with before, on the other hand it is reasonable not to behave in an opportunistic way with the new partner. In fact, the impossibility to create trustworthy relationships with few subjects does not preclude the opportunity to "temporarily" behave "in a cooperative way". The idea of the existence of cooperative behavior among subjects that know they have to cooperate endlessly or indefinitely is contemplated in the game theory. According to it, only when partners know when cooperation ends, they will be induced to behave opportunistically. As in this case partners cooperate under not well definite conditions, they do not exactly know the future and ignore if the current one is the last interaction, this is they may be induced to cooperate.

\section{The Existence of a "Lighthouse Its Important, but not Enough (Limits of Fordistic Institution in a Post-Fordistic Scenery)}

In this section it is discussed if navigation in the post-fordistic stormy sea could take advantage from the existence of a more certain regulation of the reliability of knowledge in the network. To find the solution to this question, it is above all necessary to underline that positive law is not a post-fordistic tool. Its origins are in the pre-fordistic era, then a basic turn in history takes place: The authoritarian State model is abandoned, and law-based State model is developed. Laws set non-modifiable boundaries, well-know in advance by every entrepreneur. The effect of a new law introduction is not different from technological innovation. External changes in the transformation ratios of inputs in outputs take place. Positive law, then is universal and certain: "Every subject is equal before the law". The last statement explains why this pre-fordistic tool maintains its validity in the post-fordistic era. The need for control and the rules accepts and develops the already existent tool. It is not easy to realize whether this tool can be used in the "revolutionary post-fordistic era", when certainties are thought to be "a not allowed luxury", because they mean standstill, in a continuously changing word. The existence of macro rules is undoubtedly very important in the current transition period towards post-Fordism. It is a stimulus to enter the network for potential, but shy, subject, accustomed to fordistic schemes. Once the network is created, though, the positive rule scheme should get less and less important 
representing the bases of a different situation. The foundations of networks functioning must in the fact be generated within the network itself. It is not effective to wait for trustworthy relationships among network partners to develop. However, it is necessary the partners generate their own modus operandi, a "common language" which allows communication and action relying on the good functioning of the network and on the profitability to belong to it. The development of different roles within the network is needed, too. In this way, even with extreme flexibility and without the rigid mechanism of hierarchy, it will be possible to create an effective auto-organization. In the following section a more detailed discussion of these issues will be carried on. Now the focus will be on the potential role of positive law in the transition towards post-Fordism, trying to understand if this role can be consistent with the current situation or if changes are needed. Therefore it is interesting to underline that current laws are not satisfactory at all, because they actually do not give any certainty or assurance to the operators. There is no satisfactory detailed law regarding ideas, knowledge, abilities, and know-how, by now. Therefore it is not possible to rely on a specific regulation framework to protect knowledge found on the network. A regulatory official intervention on this issue seems then necessary.

This intervention could be two-fold: New law concept could be created or a new interpretation of existing concept could be set. Some kinds of knowledge are already regulated: patents, trademarks, and copyright even on formulas and images. The problem could be solved by examining the possible application of the traditional idea of copyright to new cases. It seems necessary to understand the scope of ownership of knowledge transferred in a worldwide surrounding by a different physical support: the web page. It is interesting to underline that, in any case, the juridical solution of the problem would not be relevant if faced only within national boundaries. A significant result can be only obtained by an international harmonization process. While, as we have already said, new technologies eliminate or at least remarkable reduce the economical relevance of "space", the game rules, necessary to ensure the protection of knowledge in the network, should be the same all around the world. The juridical framework should be intended as the written expression of an ideal code of behavior, shared among all the "net-consumers", with no regard to their nationality. Facing the problem on a national level would be meaningless, because the network is by definition stateless, transversal, and transnational.

This is why conditions for network functioning have to be mainly generated within it: External rules can hardly be effective. Post-fordism is in fact the era of interaction: Several subjects (individuals, groups of individuals, firms) communicate with each other and exchange knowledge in a new way (through telematic networks), thus reciprocally growing and creating a world in which meanings and behavioral schemes are shared. To make this possible and to subsequently obtain a real share of learning efforts, the subjects must be able to rely on adequate creative abilities of their counterparts. The positive opinion cannot be based on past experiences, because as already noticed, in a context characterized by reversible productions, knowledge segments are supplied by different subjects almost every time. At the same time, this opinion cannot be based on the general consideration that laws against incorrect behavior and break of contracts exist. It is necessary that every network partner is able to ensure high quality performances. As a consequence, the problem then is to define this last idea, which is "quality" and which means "formal definition of process characteristics and of performances the manufacturer can ensure himself and the consumer”. Besides product features, the ability to satisfy consumer expectation, which are process features, becomes interesting, too.

\section{You Need to Speak the Same Language}

Network has been defined as "the result of a new way of reducing complexity". It is different from market 
and hierarchy, relies on a regulatory medium, that is the plan which concentrates information and decisions (thanks to the firm's appropriation power), the network utilizes a linguistic medium, consisting in specialized and shared language for reciprocal communication among the units. It seems appropriate to try to individuate, in general, the correct definition of "language" and the roles attributed to it, according to literature. Knowledge circulating within the network is explicit, that is, codified. We can distinguish between formal codes and languages. The former ones allow to translate a limited variety of inputs (situations) into a limited variety of outputs (answers) and therefore they are a "closed elaboration system". The latter ones, on the contrary, represent an "open elaboration system", formed by a set of basic meanings (words) and a combining grammar rules, which allow to express complicated meanings (speeches). The use of formal codes in real situations allows to obtain "information": In fact, they represent preset "keys" to the interpretation of the real word. As a code is a simplified representation of reality, this way of acting can be not profitable because a perfect correspondence between what really happens and what the preset model can interpret is not ensured. At the same time, an important advantage is obtained. "Through codification, concrete knowledge can be quietly transferred to many users, infinitely reproduced and preserved with no difficulties". If codification of informal knowledge through a code is not effective because the resulting representation is too different from reality, it becomes necessary to use an open language, instead of a closed code. "In other words, it is possible to codify knowledge in a more general way than the specific one needed for a particular problem, by expressing it in the form of basic meanings and in a grammar of allowed combinations". Formal codes and languages represent "manufacturing resources” for the firm. They are a form knowledge of more general level than solve specific and already known problems. Instead, codes and languages can be used by whoever needs them and is allowed to by the subject that codified them. They can be utilized in the decisional process, in many different cases and situations.

As codified knowledge is transferable, it can be included in the network. The creation of a virtual site where all codified knowledge owned by partners can converge creates an intangible asset of unlimited potential. Single segments of knowledge can in fact be combined in different ways by partners, according to their creative abilities, thus originating new explicit knowledge. Composed by only a few words at the beginning, language becomes richer, more flexible, and then useful to better interpret new situations coming next. In other words, once it is generated, language can also be used to modify and to produce new codes, new basic meanings, and new grammar rules. The realization of this opportunity is the most relevant existence condition of a network. Its existence is in fact not based on trust, nor on the opportunity to create cooperative relationships, nor on the existence of positive laws, not even on the certainty coming from relationships with "certified" counterparts. In fact, the lack of this factor condemns the single user to follow his own way. A group of individuals, linked to each other, not realizing that its only strength is represented by the share of individual abilities and that their codification is expensive, does not constitute a network, but another organizational form.

Metaphorically speaking, it is compared the need for participants to share a language to the need that different wooden components of the raft are firmly kept together by strong ropes. Without ropes, wooden components would separate and the sailors would fall into the sea, would have to swim among the waves.

\section{You Need to Share Tasks}

The idea of sharing learning efforts can be interpreted in two different ways. Until now, it was used with a general meaning: As the constitution of a network generates a common set of codified knowledge, at least as big as the sum of knowledge owned by each partner, it becomes convenient for each one to manage the 
development of different knowledge segments.

Once the convenience is individuated, it is then possible to identify the potential typical roles of the firms. In other words, an alternative value chain can be built, different from the traditional strategic management one, not focused on material activities performed by the firm, but on learning efforts. It is possible to distinguish some typical functions that cannot be replaced within the network, this does not mean, unlike some authors say, "to transform network into hierarchy", that is denying that network is an autonomous organizational model. The lack of structure is not the element to distinguish networks from hierarchy. The main difference is the medium utilized: authority in hierarchy and language in networks. Even a network can have a structure and more different roles necessary for its functioning.

Literature identified four typical elements that must exist at one time in order for the network to effectively work. In particular, we can distinguish two "primary" and two "secondary" roles. Primary roles are played by firms directly involved in the creation of new knowledge. First of all, "global specialists" are identified: They concentrate on the creation of new knowledge related to a single and specific segment. They design it so that it can be used in different contexts. The second typical role is a complement of the first one: "System analysts" study the different contexts in which knowledge can be used. They "deliver knowledge" to "final users", by combining available knowledge in order to satisfy clients' expectations and by influencing "the producers of specific knowledge”. They, in fact, drive the latter ones towards "high value added segments”, because these are more relevant for "final users". "Support" roles satisfy constitution and assurance expectations.

On one side it is distinguished the "meta-organizer" who constitutes the network, establishes basic requirements to enter it and the causes to get out of it: it generically controls its functioning. The meta-organizer manages the total investments in communication resources, shares the cost of basic innovation, and contractually protects intangible assets from imitation and unauthorized uses, when this is necessary. On the other side we find "connectors" who are interested in making connections among network partner easier. This aim is achieved both in physical terms with logistics and in intangible terms ensuring the quality of new network partners.

It is important to point out that the "meta-organizer" is not a manager of a hierarchal structure, but only a coordinator-sponsor: He does not have direct authority on users, he does not decide single strategies or actions, and he does not regulate interactions. Single units can autonomously choose their actions and how actively to take part in the network. In fact, they are not subjected to the meta-organizer authority nor to any other network partner authority (at least not just because they belong to the network). It is possible to think of the meta-organizer as a sort of guardian of shared knowledge. Therefore, he is virtually "authorized" only to act in protection of this asset value against any menace coming from inside or outside. In the same way, it is interesting to underline that a connector with a warranty role is not a controller: His task is not to verify network partners performance, but to help the meta-organizer to perform his tasks, by verifying that new partners are respecting certain standards.

Metaphorically speaking, if the raft has to face waves, subjects must share tasks so that every operation needed for navigation is performed.

\section{Fordistic Organization Trying to “Change Their Dress”: Promos-Business Agency of Milan Chamber of Commerce Case Study}

In this section the focus is on the efforts of a public institution-the Milan Chamber of Commerce-to 
effectively perform its support role to firms in the dynamic post-fordistic era. It would be discussion on the nature of its contribution - certainly very innovative - trying to understand if its role is "related to a network".

In order to strengthen its support to firms, especially small and medium-sized, in their way towards local marketing and internationalization, in 1991, Milan Chamber of Commerce constituted a specific agency for promotion and development of international activities, called Promos. Promos aims at promoting Milan firms activities abroad, through advisory and assistance services, through a policy of relationships with national and international institutions and organizations, and through information and communication instruments.

In the pursuit of its goals, Promos has set up a network of 12 foreign offices to establish a footprint on the main international markets and to promote Milan and Lombardy. Its services aim at facilitating the promotion of commercial, technological, and manufacturing agreements, among Milan and foreign firms. Therefore, Promos organizes complex projects, by defining objectives, geographical areas, operational and implementation procedures of the project.

According to these elements, the project is launched, that is its existence is communicated to Milan firms through a multi-media instrument-fortnightly magazine "Mercatoglobale" (Global Market)—diffused through the Internet and printed on paper, too.

Promos selects some of the firms interested in the projects, by detailed analyses which allow it to warrant the quality of their performances, in front of potential foreign partners.

In order to spread the initiative, Promos predisposed some "desks" in some target countries. The desks have the same role of Milan office in the launch of the project and in the selection of firms, on the basis of the quality level of project and on the basis of the quality level of performance. When the project involves countries where desks have not been established, Promos relies on institutional partners which perform these tasks, on the basis of specific agreement. Usually, these partners are Italian embassies in target nations, local chambers of commerce, local industrial associations, associations of Italian firms working abroad.

Once the network is organized, Promos does not abandon the partners, but organizes the first meetings and, in some cases, goes along with the Italian part to the Italian part of the foreign country, following the development of the single stages of the project. In order to better illustrate the activities performed by the agency, it would be discussed one of its many projects towards the Mediterranean and Gulf area. It is designed for furniture manufactures wanting to find a partner in Libya, Morocco, Syria, and Tunisia (Mediterranean and Gulf). Promos objectives with this project are the following:

- Promotion and economic cooperation for firms wanting to individuate partners in Mediterranean countries;

- Creation of permanent networks for Lombardy firms already operating in those countries;

- Maintenance and updating of contact networks already established in those countries;

- Promotion of economic transaction and of cooperation for groups of furniture manufacturers.

The objective is generic enough to incorporate proposals coming from single firms and later developed during interaction between counterparts, after the start of the project. It is in fact interesting to observe the details of operational procedures:

- Identification of firms and service providers potentially interested in the project. Direct meetings with each firm, about: (1) structural firm data; (2) information or technology; and (3) statement of interests in potential investment or commercial cooperation opportunities;

- Direct survey in target countries, in order to identify projects an cooperation hypotheses through direct meetings with potential partners; 
- Check of projects and opportunities;

- Technical and commercial inspections in Mediterranean countries with interested firms and direct meetings with potential partners.

Promos is a network creator, a sponsor for partner abilities, and an interaction "facilitator", because it organizes technical and commercial meetings in foreign countries. However, specific projects are constituted and proposed by potential partners.

This new Chamber of Commerce role is certainly different from the traditional one: The institution appears to have "changed its dress (and its name)" in order to give a really useful service. In this way, at first glance, it seems to have assumed two of the roles discussed in previous section four: the one of the meta-organizer and the one of connector with sponsor features.

First of all, Promos can be considered as a meta-organizer, because it allows the birth of a new "object”: a set of interrelation among subjects not linked before.

A general objective the partners must achieve is stated. In this way, the opportunity for a meeting is created and the birth of an interaction is facilitated: A shared language - the basic element of the network —is generated. Promos organizes personalized programs for business to business (B2B) meetings and visits to selected local counterparts. Also, it can be considered as a connector with a sponsor role, because it ensures the quality of activities performed by networks partners, by directly promoting analyses, through its local offices, or relying on a "network of sponsors". This function is not universal: Services are not destined to everybody but only to selected Italian and foreign subjects. This is typical of every connector, being a public institution or not. In order to identify the best available knowledge, in fact, the connector-sponsor, as previously defined it, carries on a research work and then selects the best candidates to sponsor (that is, it "scans the available documentation").

Some characteristics distinguish Promos from an ordinary "network operator". As promos is a subsidiary of a public institution, Milan Chamber of Commerce:

- It does not have the objective of creating and operating only one network. Its institutional mission is to represent a sort of "network creation laboratory". Only in the last year, Promos had promoted about 2,000 companies and several projects, similar to the one we just analyzed, in different industrial sectors as: agroindustrial, automotive, transportation, energy, environment, automation, security, aerospace, and geographical areas as in: Europe, Asia, North America, Latin America, Mediterrenean and Gulf, Sub-Saharan Africa;

- It is clear that this modus operandi does not allow to define Promos "a network operator", that is a subject operating in and for the network. Promos can be compared to a company's promoter, whose role is to generate the starting entrepreneurial idea and to begin a project other subject will later carry on;

- It must pursue a specific task: the development of firms operating in Milan area. This characteristic can be alternatively interpreted as a limit to its meta-organizational activity, or in a simply way, as a requirement for firms wishing to participate to the network.

What it was discussed does not allow to consider Promos a perfect post-fordistic operator. The initiative virtually constitutes a hybrid, certainly generated by a deep understanding of current changes. The hybrid is aimed at mediating between the ancient need for "market organization" and the new need for a "network creation and internationalization”. 


\section{Conclusions}

In the post-fordistic stormy sea, staying apart, frightened waiting for a white, safe, big ship to pass or trying to resist to the waves continuous movement is not profitable at all. Firms must realize that it is better to face danger and to "ride the waves". Therefore, an easy-to-manage boat is needed: a "raft". The raft must resist: Its wooden components should be safely bound and the navigators have to share tasks in order to ensure the performance of each navigation activity. Everyone should concentrate on the chosen role, so that the others can consider his presence as a necessity. Everyone has to act, taking into account the useful advice others can give. The dim light of the far lighthouse can help, but it can identify only a part of navigation dangers.

\section{References}

AA.VV. (1995). Network: Network analysis in the social science (Reti: L'analisi di network nelle scienze sociali). Italy: Donzelli Publisher.

AA.VV. (1996). Network in marketing. Italy: Iacobucci Publisher.

Bellandi, G. (1989). Quality strategic management in the relation between market-company (La gestione strategica della qualità nei rapporti azienda-mercato). Milan: Giuffrè Publisher.

Boyer, R. (1988). Looking for fordism alternatives: Years 80 (Alla ricerca di alternative al fordismo: gli anni '80). Stato $e$ Mercato, 24, 387-423.

Ceccanti, G. (1992). The systematic value capacity (Il valore delle capacità). Sinergie, 29, 51-52.

Coleman, J. S. (1998). Social capital in the creation of human capital. American Journal of Sociology, 94, 95-120.

Cozzi, G. (1986). Information technology diffusion to market forms: First reflection aspects (Diffusione delle tecnologie dell'informazione a forme di mercato: primi punti di riflessione). Economia e Politica Industriale, 50, 227.

Di Bernardo, B. (1987). Value chain and strategic surplus: What's new in terms of complexity industrial theory (Catena del valore e surplus strategico: cosa c’è di nuovo sul fronte della teoria della complessità industriale). Economia e Politica Industriale, 54, 183-207.

Di Bernardo, B. (1989). Flexible capitalism network: Beyond the dichotomy hierarchy-market (La rete del capitalismo flessibile:oltre la dicotomia gerarchia-mercato). Economia e Politica Industriale, 64, 165-207.

Dubini, P., \& Aldrich, H. (1989). Networks and processes of business development (Le reti e i processi di sviluppo delle imprese). Economia e Politica Industriale, 64, 363-375.

Fukuyama, F. (1995). Trust: Social virtues and the creation of prosperity. New York: Free Press.

Giddens, A. (1994). The modernity consequences: Trust and risk, safety and danger (Le conseguenze della modernità: Fiducia e rischio, sicurezza e pericolo). Bologna: Il Mulino.

Giulivi, A. (1997). Computer networks and organization process in the virtual company (Le reti telematiche e organizzazione di processo nell'impresa virtuale). Proceedings from the Conference of The Company Boundaries: Logic for the Management and Regulation. AIDEA Giovani.

Grandori, A. (1989). Efficiency and equity of inter-organizational networks: A perspective negotiating (Efficienza ed equità delle reti inter-organizzative: una prospettiva negoziale). Economia e Politica Industriale, 64, 349-350.

Grandori, A. (1989). Inter-organizational networks: Planning and negotiation (Reti inter-organizzative: progettazione e negoziazione). Economia e Management, 7, 29-31.

Kreps, D. M. (1990). Game theory and economic modeling. Oxford: Claredon Press.

Lamprecht, J. L. (1996). The application of UNI EN ISO 9000 in small enterprises (L'applicazione delle norme UNI EN ISO 9000 nelle piccole aziende). Milano: Franco Angeli Publisher.

Lorenzoni, G., Grandi, A., \& Boari, C. (1989). The network organizations: Three basic concepts (Le organizzazioni a rete: tre concetti di base). Economia e Politica Industriale, 64, 283-310.

Nonaka, I. (1994). How an organization creates knowledge (Come un organizzazione crea conoscenza). Economia e Management, 3, 31-48.

Nonaka, I., \& Takeychi, H. (1995). The knowledge creating company. Oxfords: Oxford University Press.

Pfefer, J., \& Salancick, G. R. (1978). The external control of organizations: A resource dependence perspective. New York: Harper \& Row. 
Pindyck, R. S., \& Rubinfeld, D. L. (1992). Microeconomy (Microeconomia). Italy: Zanichelli Publisher.

Porter, M. E. (1996). Competitive advantage (Il vantaggio competitivo). Milan: Edizioni di Comunità.

Powell, W. W., \& Di Maggio, P. J. (1991). The iron cage revisited: Institutional isomorphism and collective rationality in organizational fields. Chicago and London: The University of Chicago Press.

Riva, P. (2001). Non-financial Information in (Italian) Annual Reports: Disclosure of Performance Measures: An Empirical Survey (Informazioni non finanziarie nel sistema di bilancio: Comunicare le misure di performance: Analisi empirica) (pp. XIII-226). EGEA.

Riva, P. (2002). The importance of non-financial information in the financial statements (L'importanza delle informazioni non finanziarie nel sistema di bilancio). Maggioli Journal of IR, 4, 23-31.

Riva, P. (2009). The review of prospective data in accordance with ISAE 3400: International auditing principle application to the independent auditor attestation provided by the bankruptcy law (La revisione dei dati prospettici secondo l'ISAE 3400 L'applicazione del principio internazionale di auditing alle attestazioni del professionista previste dalla legge fallimentare). Maggioli Journal of IR, 2, 55-61.

Riva, P., \& Quagli, A. (2005). Do financial websites meet the users' information needs? A survey from the Italian context. Retrieved from http://hq.ssrn.com

Rullani, E. (1987). The enterprise as an artificial system: Learning and languages in the evolutionary approach of complexity (L’impresa come sistema artificiale: Linguaggi e apprendimento nell'approccio evolutivo della complessità). Economia e politica industriale No. 56 .

Rullani, E. (1989). Network economy: The languages as production means (Economia delle reti: i linguaggi come mezzi di produzione). Economia e Politica Industriale, 64, 132.

Rullani, E. (1992). Economics of intangible resources (Economia delle risorse immateriali). Sinergie, 29, 18-19.

Rullani, E., \& Beccatini, G. (1993). Local system and the global market (Sistema locale e mercato globale). Economia e Politica Industriale, 80, 25-47.

Rullani, E., \& Di Bernardo, B. (1984). Evolution: A new paradigm for the firm theory and technological change (Evoluzione: un nuovo paradigma per la teoria dell'impresa e del cambiamento tecnologico). Economia e Politica Industrial, 42, 39-106.

Rullani, E., \& Di Bernardo, B. (1990). The management and the machines: Evolutionary theory of the enterprise (Il management e le macchine: Teoria evolutiva dell'impresa). Bologna: Il Mulino.

Rullani, E., Di Bernardo, B., \& Vaccà, S. (1986). Technological change and enterprise economy (Cambiamento tecnologico ed economia dell'impresa). Economia e Politica Industriale, 50, 79-124.

Sanna Randaccio, F. (1987). Notes on the production internationalization of Italian firms (Note sull'internazionalizzazione produttiva delle imprese italiane). Economia e Politica Industriale, 55, 219-233.

Vicari, S. (1991). The living companies: Itinerary in a different conception (L'imprese vivente: Itinerario in una diversa concezione). Milano: ETAS.

Vicari, S. (1995). Towards resource based management (Verso il resource based management) (pp. 9-48). Milan: EGEA.

Zucker, G. L. (1991). The role of institutionalization in cultural persistence. In W. Powell, \& P. DiMaggio (Eds.), The new institutionalism in organizational analysis (pp. 83-110). Chicago: University Chicago Press. 